ERRATUM

\title{
Erratum to: A collection of 505 papers on false or unconfirmed ferroelectric properties in single crystals, ceramics and polymers
}

\author{
Zbigniew Tylczyński \\ Faculty of Physics, Adam Mickiewicz University, Uniwersytetu Poznańskiego 2, Poznań, Poland \\ E-mail: zbigtyl@amu.edu.pl
}

Erratum to: Front. Phys. 14(6), 63301 (2019)

https://doi.org/10.1007/s11467-019-0912-5

In the original publication of the article, there are some mistakes regarding the sequence of references. Some references are mislocated. Here is the new version of the full paper.

*The online version of the original article can be found at: https://doi.org/10.1007/s11467-019-0912-5,

http://journal.hep.com.cn/fop/EN/10.1007/s11467-019-0912-5. 